\title{
The main factors affecting the character of housing construction in Iran
}

\author{
Valeriy Kazarnovskiy ${ }^{1, *}$, and Mohammad Kazem Hadavi ${ }^{1}$ \\ ${ }^{1}$ Moscow State University of Civil Engineering, 26, Yaroslavskoye Shosse, 129337, Moscow, Russia
}

\begin{abstract}
The article examines the main objective factors affecting the development of housing construction in Iran. In terms of population per unit area, Iran ranks 21 st in the world. However, the density of the population varies by territory, this is because only $30 \%$ of the territory has a relatively sufficient amount of water to provide the population. The population is unevenly distributed. It is characteristic that in different regions of Iran the urban population is different in its specific weight. So, in the Tehran region is $27.2 \%$, and in Chakharmakhal and Bakhtiari - $0.87 \%$ of the total population. Population growth stimulates the development of cities and will require an increase in the number of dwellings, as well as improving their quality. As you know, the climate of Iran has a pronounced change of seasons, and different geographical regions of Iran differ in their climatic conditions. Particular attention should be given to architectural and construction recommendations that affect the design of medium-height houses in seismically hazardous areas, especially in Central Iran. At present, the state policy of Iran in the field of housing construction is carried out in three directions - three types of construction: free housing, mixed construction, social housing.
\end{abstract}

\section{Demographic factor}

The article examines the main objective factors that influence the development of housing construction in Iran, including natural, social and cultural

Demography includes such concepts as nationality, religion, population, its age and sex composition, structure (urban, rural, nomadic, etc.), as well as the movement and development of the population [1-4, 14].

In terms of population per unit area, Iran ranks 21 st in the world. However, the density of the population varies by territory, and it is explained by the fact that only $30 \%$ of the territory has a relatively sufficient amount of water to provide the population. The population is unevenly distributed (Fig. 1).

\footnotetext{
* Corresponding authors: angela-1309.m@yandex.ru
} 


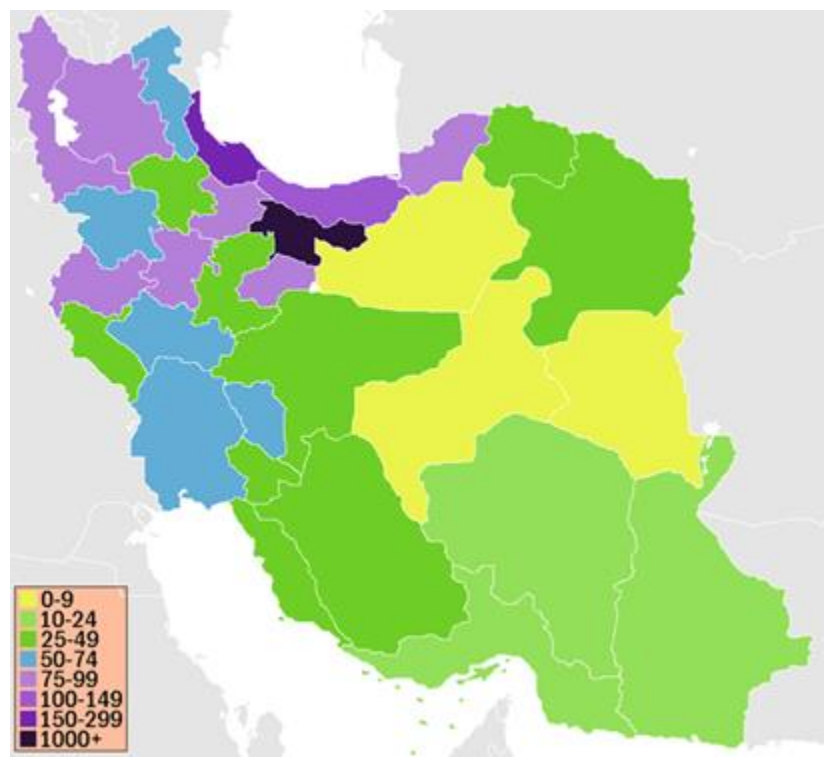

Fig. 1. Map of population density in Iran (people / sq. Km).

The northern (Caspian Sea) and northwestern parts of the country are most densely populated (Mazandaran, Gilan, Khuzestan, Eastern and Western Azerbaijan), where the density reaches 30 people per square kilometer, here live more than $2 / 3$ of the population. In the central part of the country, density is reduced to 18 people per square kilometer, the lowest in the south-east of the country is 1 person / sq. $\mathrm{km}$. The fifth part of the population lives in Tehran, the population density is 26 people / sq. km [5].

According to the data of 1994, the total population of the country had a tendency of uneven but constant growth. The number of families is also growing, while the average family size in the 1970s and 1980s increased by one-hundredths, but since the mid-1990s, its decline has been outlined. Until the early $1950 \mathrm{~s}$, about $80 \%$ of the population lived in villages. Later the movement of villagers to the cities began. By the beginning of the new millennium, the urban population was already about $2 / 3$ [12].

It is characteristic that in different regions of Iran the urban population is different in its specific weight. So, in the Tehran region is $27.2 \%$, and in Chakharmakhal and Bakhtiari $0.87 \%$ of the total population.

Population growth stimulates the development of cities and will require an increase in the number of dwellings, as well as improving their quality.

In general, the population of Iran is quite young, although there is a gradual aging of it and especially of the urban population.

The comfort of living is related to the number of rooms per person. Here there is a large backlog of Iran from the leading European countries. By the end of the 1980s, in a city dwelling there were up to 1.5 people per room, in the country as a whole this figure was 1.7 people per room, while in Italy, for example, it was 0.8, in Belgium - 0.5, in France - 0.6, and in Iraq - 2.14 [10].

The relationship between the number of rooms in an apartment and the number of people living in it is generally accepted in Russian practice as: $\mathrm{K}=\mathrm{P}, \mathrm{K}=\mathrm{P}-1, \mathrm{~K}=\mathrm{P}-2, \mathrm{~K}=\mathrm{P}+$ $1, \mathrm{~K}=\mathrm{P}+2$, etc, where $\mathrm{P}$ denotes the number of people living in an apartment, $\mathrm{K}$ denotes the number of rooms. Formulas $\mathrm{K}=\mathrm{P}-1, \mathrm{~K}=\mathrm{P}-2$, etc. show that the number of rooms in the apartment, respectively, one, two, etc. less than the number of family members and vice versa, the formulas $\mathrm{K}=\mathrm{P}+1, \mathrm{~K}=\mathrm{P}+2$, etc. indicate that the number of rooms in the apartment is one, etc. more than the number of family members [13]. 


\section{Climatic factors}

The main factors determining the type of climate are geographical latitude and altitude above sea level. Iran is located in the northern hemisphere and occupies a position between 25 and 40 parallels, so Iran's climate is warm. Most of the country is located at an altitude of more than 475 meters above sea level. The location of large water bodies, the Caspian Sea in the north and the Persian Gulf in the south, also influences the climate, however, the mountain ranges Elbrus and Zagros prevent the distribution of moist sea air deep into the country and limit the influence of small-area sea winds [1]. According to the latest research conducted in 2007 by the COREC method by the famous Iranian meteorologist Mr. Ganja, four main types of climate are distinguished, depending on the terrain and other geographical features [3]:

- moderately humid climate (the southern coast of the Caspian Sea);

- relatively cold climate (western foothills of Iran);

- dry hot climate (the central plain of Iran);

- $\quad$ hot humid climate (southern coast of Iran) (Fig. 2).
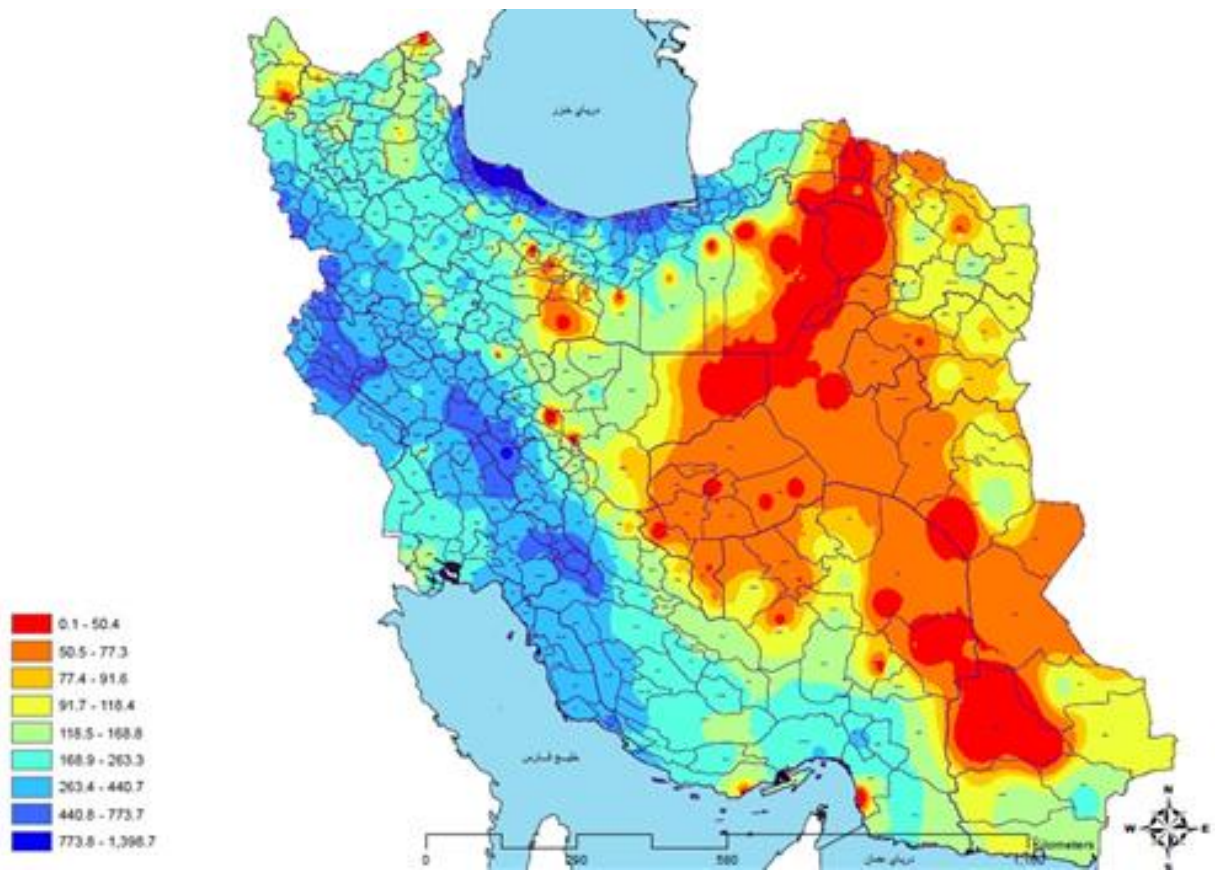

Fig. 2. Precipitation map of Iran.

\subsection{Specific features of architecture and town planning in Iran, depending on climatic conditions}

The climate of Iran has a pronounced change of seasons, and different geographical regions of Iran differ in their climatic conditions. All this affect the architecture and urban planning features as well as the design, technology in Iran (Fig. 3, Fig. 4) [8]. 


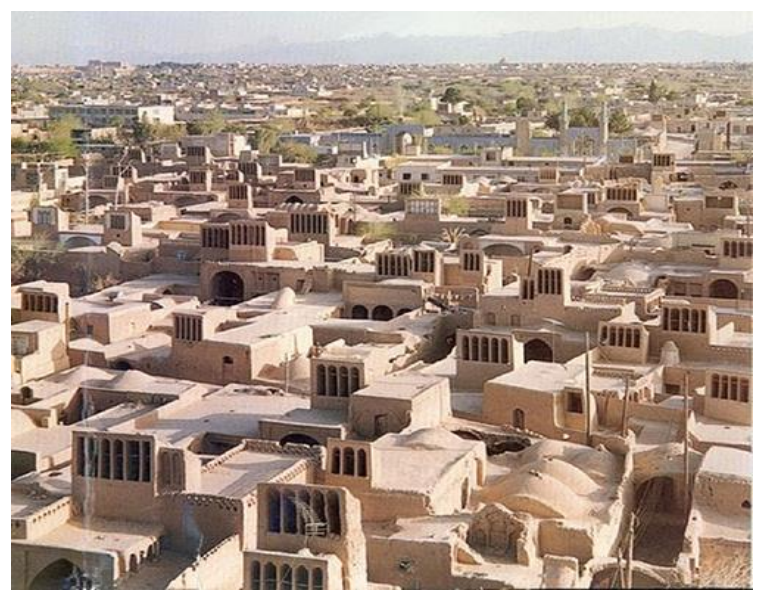

Fig. 3. Urban environment in an area with a dry and hot climate.

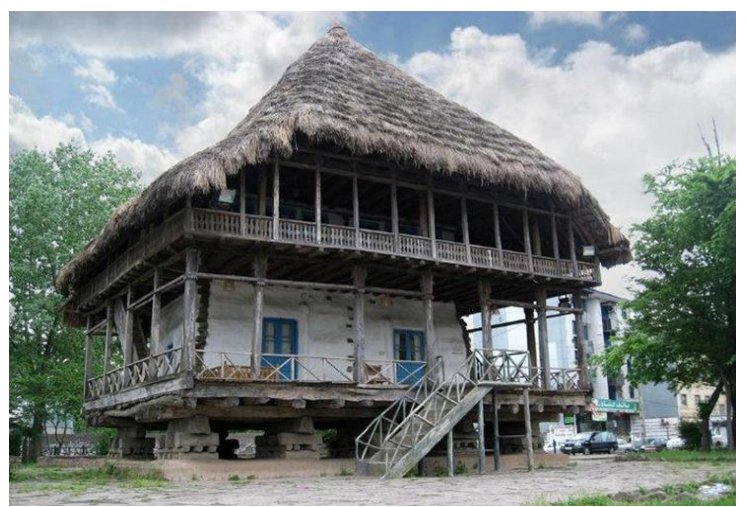

Fig. 4. Typical house in a temperate-humid climate.

\subsection{Architectural and construction solutions in seismically dangerous zones of Iran, applied in accordance with the state law of the Islamic Republic of Iran No. 2800}

Particular attention should be given to architectural and construction recommendations that affect the design of medium-height houses in seismically hazardous areas, especially in Central Iran [6].

The law provides for a ban on:

1. construction of buildings with clay walls;

2. construction in places where faults in the ground pass;

3. construction in areas with unstable soils (for example, near the sea coast, as well as in deserts) [11].

\section{Factor of tradition in the construction of Iran}

This factor is determined by the importance of home for the life of families in Iran, the role of tradition and demography in the formation of housing as a place where the best human values are created, where a happy personal life is taking place. The most important requirement for a dwelling is its harmonious correspondence to the principles of life. For 
Iran, it is important that religious beliefs do not conflict with culture and, in particular, with architecture [7].

\section{Features of modern housing in Iran}

For the research of the issue, the materials of the large Iranian firm Sarmaye Gozarie Maskan (SGM), the materials of the specialized conference on housing in Iran, the Collection of articles of the 3rd seminar "The Policy of the Development of Housing in Iran" were used. The state policy of Iran in the field of housing construction is carried out in three directions - three types of construction:

Free housing, which is built by wealthy families and is privately owned. The state in this type of construction does not act as an assistant, but only as a controller for the implementation of the rules of erection and compliance with standards. The share of this construction in the housing market reaches $53 \%$.

A mixed type of construction, which is built with state help for the developer. In urban construction the total area of the house (apartment) should not exceed 100 sq.m. Then the family receives a subsidy for construction in the form of a loan at a certain interest, cheap land; is assisted in the exploration of water, providing electricity, gas. The state encourages this type of construction. The family, therefore, can build a dwelling in accordance with modern requirements. The share of this type of dwelling is $30 \%$ of all urban housing construction.

Social housing is provided for low-income families and is built on the basis of a minimum program of standards (up to 50 sq.m total area). Usually apartments are populated by a young generation or poor people. These dwellings are built below the ordinary standards. Not only the state, but also banks, social bodies participate in their construction, while the savings of the families themselves are also used. These apartments are either rented or rented with a mandatory purchase later. The share of such dwellings in the market is $16 \%$ [9].

As criteria for the evaluation of architectural and planning solutions of sectional residential buildings are used:

- the number of storeys and the length of buildings, the number of apartments facing the staircase or the stairway, the width of the building's enclosure, as a measure of the costeffectiveness of the solution, as well as the compactness of the layout associated with the reduction of heat losses [15];

- the possibility of airing the apartments through the openings, as an indicator of the intensity of air exchange and the reduction in air temperature in summer (winding through straight through, angular, through the shaft or the landing of the staircase-elevator unit) [4];

- the orientation of the premises in accordance with (not in accordance with) the recommendations adopted for the zone as a whole, or for a specific city;

- the shape of the building in terms of plan and section and the relative location of the capital walls (with frameless solutions) as indicators of the seismic resistance of the building. The form in the plan is desirable simple and compact - round, polygonal, square or approaching a square, without protrusions, depressions and fractures of walls. Internal walls: frame frames, diaphragms should be placed evenly and symmetrically relative to the center of gravity of the building [2].

\section{References}

1. H. Bahrainy, Environmental Studies 2(41), 465-482 (2015)

2. S. Hemati, Architecture and Urban Design (Tehran, 2015)

3. Iran Meteorological Organization, http://www.irimo.ir 
4. M. Kasmaei, Architecture and Climate (Isfahan, 2002)

5. R. Mirzai, Residential houses of medium height, built by industrial methods for hot-dry climatic zone, Thesis (Moscow, 2009)

6. B.R. Lopshuna, The dwelling of the peoples of Iran. Types of traditional dwelling of the peoples of South-West and South Asia (Moscow, 1981)

7. A. Mohamadi, Architecture and Culture (Tehran, 2000)

8. M. Rafi, Urban housing, analysis of the main problems in the design of housing in Iran (Tehran, 1993)

9. M. Sadr, Urban Study 3, 34-43 (2012)

10. H. Saremi, City Identity 10, 91-102 (2002)

11. Seismic Code in Building Regulations of Iran. Fourth edition (Housing and Development Research Center, Tehran, 2016)

12. Statistical Centre of Iran, https://www.amar.org.ir

13. A.K. Shreiber, Construction production. Encyclopedia (Stroiizdat, Moscow, 1995)

14. I.P. Voiku, Demography (Peskov State University, Peskov, 2013)

15. Dwelling for the south. Recommendations for the design of residential buildings and residential buildings for the IV climatic region of the USSR (Tashkent, 1979) 